\title{
El discurso del despido libre en España: una reflexión sobre el papel de los mitos y los prejuicios en las políticas de empleo españolas
}

\author{
Carlos Jesús FERNÁNDEZ RODRÍGUEZ \\ Facultad CC. Económicas, Departamento de Sociología \\ Universidad Autónoma de Madrid \\ carlos.fernandez@uam.es \\ Miguel MARTÍNEZ LUCIO \\ Manchester Business School \\ University of Manchester \\ miguel.martinezlucio@mbs.ac.uk
}

Recibido: 08-04-2013

Aceptado: 26-09-2013

\begin{abstract}
RESUMEN
Esta contribución tiene como objetivo intentar comprender las complejidades que subyacen bajo el debate del despido libre, uno de los más relevantes en este contexto de crisis económica. Se centra en la forma en que el debate se ha construido y cómo, en el caso español, delimita las líneas rojas de toda discusión en relación a las relaciones industriales, el mercado de trabajo e incluso la economía en general. Este discurso del despido libre llega a ser incluso vital a la hora de definir la forma en que la política de empleo se prescribe y se limita. Esto nos obliga a intentar desentrañar las intenciones políticas que se encuentran detrás de las medidas sugeridas por empleadores y académicos asociados. Estas son además el objeto de influencias políticas e ideológicas más amplias que generan una perpetuación de los mitos en relación a los países y sus economías nacionales.
\end{abstract}

Palabras clave: despido libre, despidos, flexibilidad, discurso político, caso español

\section{The discourse on free dismissal in Spain: a reflection on the role of myths and prejudices in Spanish employment policies}

\begin{abstract}
This contribution is intended to try to understand the complex issues that underlie this debate on the free dismissal that has become very important in this context of economic crisis. It focuses on the way the debate is shaped and how it frames discussion about industrial relations, the labour market and even the economy within the context of Spain. Regardless of differences that exist on the substantive issues of flexibility and dismissal, the free dismissal discourse is vital for defining the way policy is prescribed and constrained in the case of Spain. This forces us to understand the underlying politics and issues around which employers and academics shape policy and politics. They are also the subject of broader ideological and political influences that lead to a perpetuation of myths about the economy and national systems.
\end{abstract}


Keywords: free dismissal, dismissals, flexibility, political discourse, Spanish case

REFERENCIA NORMALIZADA

Fernández Rodríguez, C.J., Martínez Lucio, M. (2013). "El discurso del despido libre en España: una reflexión sobre el papel de los mitos y los prejuicios en las políticas de empleo españolas". Cuadernos de Relaciones Laborales, Vol. 32, núm.1, p. 191-219.

SUMARIO: Introducción: mercado de trabajo y política. 1. Una revisión del debate sobre el despido libre en España. 2. La influencia del discurso del despido libre en las agendas de las relaciones industriales españolas. 3. Un discurso sobre el empleo de una economía liberal. 4. Conclusiones. 5. Bibliografía.

\section{Introducción*}

El análisis de la flexibilidad en el mercado de trabajo ha sido y es uno de los temas clásicos en disciplinas como la economía del trabajo o la sociología del trabajo (Rubery y Grimshaw, 2004). Habitualmente la mirada de los académicos dentro de estas disciplinas se ha centrado en debates en torno a la teoría del capital humano y en análisis más o menos formales de la estructura del mercado de trabajo, con especial atención a fenómenos particulares del mismo como las situaciones de dualismo o segmentación. Mientras tanto, entre las perspectivas cercanas a las relaciones industriales, la tendencia ha sido la de estudiar la forma en que un contexto económico y social determinado termina moldeando la política de empleo y el marco regulador de las relaciones laborales, para analizar desde aquí cómo las políticas y marcos legales resultantes definen el grado de flexibilidad del mercado de trabajo (Boyer, 1988). Existe, de este modo, un interés creciente en conocer por ejemplo cómo se diseñan, a partir de la regulación estatal existente, los mecanismos de entrada (la contratación) y la salida (el despido) dentro del mercado de trabajo, en coherencia con una preocupación cada vez mayor por el conocimiento de los distintos contextos de regulación industrial existentes y por los diferentes modelos de capitalismo (Coates, 2000; Hall y Soskice, 2000; Amable, 2003). Esto supone comprender que el mercado de trabajo y todo lo que le rodea está atravesado por un complejo número de procesos micro y macro dentro de un contexto institucional concreto de regulación (Blyton y Martínez Lucio, 1995), cuyas interacciones, a menudo conflictivas, tendrán como resultado la emergencia de diferentes maneras de entender tanto la flexibilidad como de diversas formas de establecer los límites del debate en relación a la misma. Por tanto, el rol que juega el contexto económico, político, ideológico y social es vital, ya que como han señalado Locke y Thelen (1995) los sistemas de relaciones laborales no sólo tienen diferentes resultados en función del funcionamiento de sus procesos institucionales, sino asimismo de sus peculiaridades nacionales en las que el peso de la historia no es, en absoluto, irrelevante.

* Este trabajo ha contado con la financiación del proyecto de investigación del Ministerio de Economía y Competitividad con la referencia CSO2011-29941. 
Siguiendo esta perspectiva, es necesario enfatizar por tanto que la evolución de la regulación del mercado de trabajo no es el simple resultado de la lógica de la economía o de discusiones económicas "racionales", pues buena parte de los elementos de la discusión pertenecen al ámbito de lo político y lo ideológico. Tenemos así, por ejemplo, que tener muy en cuenta los contextos históricos que han influido en la conformación de las estrategias tanto de las élites políticas como de los agentes y movimientos sociales. Estos factores históricos influyen en las preocupaciones y proyectos en relación al papel del Estado en la sociedad y la economía, como lo prueban perspectivas tan poderosas en la actualidad como las neoliberales: su fuerza o desarrollo van a depender, en gran medida, de la rearticulación de discursos anteriores y problemas heredados (Laclau y Mouffe, 1984; Hall, 1988; Fairclough, 1989), y su éxito y/o hegemonía va a depender de la medida en que sean capaces de combinar y recoger otros discursos y debates ya establecidos previamente (Fairclough, 1995). En este sentido, la emergencia de alternativas posibles a la forma hegemónica de concebir las relaciones industriales en un determinado ámbito nacional va a estar limitada, en gran parte, por el hecho de que dichas alternativas deben insertarse en un espacio previamente ocupado por otros discursos y preocupaciones políticas ya consolidados. Todo puede someterse a discusión, pero sólo en la medida en que los actores sociales que defienden la alternativa sean capaces de visibilizar las contradicciones existentes y desafiar las concepciones dominantes con un apoyo social suficiente. Si esto no es posible, nos hallaremos ante la ausencia de un desafío real, lo que termina reforzando el orden dominante al convertir el modelo hegemónico de concepción de las relaciones de empleo en mero sentido común y en la única forma posible de hacer las cosas ("no hay alternativa"). Por tanto, analizar y evaluar ese discurso hegemónico se va a convertir en una cuestión fundamental, pues permite el que sea convenientemente comparado y contrastado. De hecho, el desarrollo de comparaciones "previamente seleccionadas" será una parte fundamental tanto en las estrategias de legitimación como de justificación del abandono de un determinado modelo de relaciones industriales (Martínez Lucio, 2002).

Este artículo va a centrarse en analizar cómo se han desarrollado estos debates sobre el modelo de relaciones industriales en España, prestando particular atención a una cuestión que se ha convertido, en buena medida, en el epicentro de buena parte de los conflictos y fricciones en el terreno de las relaciones industriales: el problema de los costes del despido ${ }^{1}$ y el "despido libre" ${ }^{2}$, eje de las últimas

${ }^{1}$ A lo largo de este texto no entraremos a realizar una valoración de los aspectos económicos de los costes del despido, algo que se ha recogido en numerosas investigaciones (ver por ejemplo Malo y Toharia, 1999; Malo, 2005), ni tampoco en las implicaciones de carácter jurídico-institucional (donde existen numerosos trabajos, ver por ejemplo Baylos, 2003; Valdés Dal-Ré et al, 2005; o Valdés Dal-Ré et al, 2011), sino que nos centrarnos en los aspectos discursivos de este debate. 
reformas del Estatuto de los Trabajadores y que ha gozado de particular atención política y mediática en los debates abiertos acerca de cómo resolver la crisis económica que padece España. El texto comenzará revisando la manera en la que se ha construido el discurso sobre el despido libre en España, con énfasis en la forma en que está influyendo sobre debates más amplios como la configuración de las relaciones industriales, el mercado de trabajo e incluso la estructura productiva de la economía española. Desde aquí, intentaremos comprender las estrategias que utilizan los representantes de los empleadores y un grupo de académicos para reformar las políticas de empleo y dotarlas de una orientación política específica, reformulando la agenda de las relaciones industriales, para desde ahí reflexionar sobre sus implicaciones y limitaciones. Haremos especial hincapié en la importancia que este discurso va a tener como aglutinador de la patronal española, creando así un sentimiento de adhesión a un proyecto común en un colectivo por otra parte fragmentado y a un proyecto común. Nuestro objetivo es el de mostrar al lector que las controversias que forman parte del debate sobre el mercado laboral están construidas dentro de un contexto de regulación específico (Blyton y Martínez Lucio, 1995), lo que implica que, como han indicado Locke y Thelen (1995), las cuestiones de identidad y valencia política específicas plantearán diferentes problemas en distintos contextos nacionales. De este modo, los debates sobre la regulación de algo como los costes de despido van a estar expuestos a influencias ideológicas y políticas que pueden contribuir a la construcción y perpetuación de determinados mitos, como veremos a lo largo de estas páginas.

\section{Una revisión del debate sobre el despido libre en España}

El mercado de trabajo español ha estado, desde la consolidación de la democracia, afectado por una serie de problemas que han suscitado el interés y preocupación por parte de los diferentes gobiernos, los agentes sociales y la población española. El problema fundamental ha sido sin lugar a dudas el elevado desempleo que se ha padecido a lo largo de los últimos treinta años de forma casi crónica (desde 1980 hasta la actualidad, la tasa de desempleo ha superado el 10\%

${ }^{2}$ Es importante aclarar que en este texto utilizamos el término "despido libre" como una etiqueta que resume con fuerza suficiente un determinado debate en el terreno de las relaciones laborales, más que como una verdadera noción sobre la que se estén discutiendo las reformas (aunque podría ser un posible, aunque extremo, objetivo final de estas). Rara vez, se expresan las reivindicaciones, sean a favor o en contra, de manera desnuda hablando del "despido libre" (entendiendo este por despido por mera voluntad del empresario y sin costes monetarios). La patronal no alude explícitamente a un objetivo de despido libre con ese nombre directamente, ni lo reclama, sabiendo que es un objetivo controvertido, por lo que procede a utilizar eufemismos en su lugar como reformas, modernización, etc. 
salvo en un breve período de tres años entre 2005 y 2008, manteniéndose por encima del $15 \%$ durante la mayor parte de este tiempo), hasta el punto de convertirse, tal y como han atestiguado las diferentes encuestas de opinión (particularmente los barómetros publicados por el CIS) en uno de los problemas centrales del país para la sociedad española, debido a su profundo impacto social (al que se han dedicado incontables trabajos: ver a modo de ejemplo Recio, 1994; Bilbao, 1999; Toharia, 2003; Valdés Dal-Ré et al., 2005; Aragón y Lazcano, 2011). Además, esta tasa de desempleo ha variado de forma significativa, alternando períodos de crecimiento del empleo más o menos sostenidos (coincidiendo normalmente con fuertes subidas del PIB, por encima del 3\%) con momentos de fortísima destrucción de puestos de trabajo, en los que una crisis económica se lleva por delante en pocos meses todas las ganancias en el empleo de períodos anteriores. Esto es, el mercado de trabajo español es extremadamente dependiente de la evolución de los ciclos económicos. La profunda crisis económica actual supone un ejemplo representativo de esta situación: así, si durante el año 2007 se alcanzaba por primera vez (en el segundo trimestre) el dato más bajo de los últimos treinta años (un 7,95\%) tras más de una década de crecimiento económico, la crisis económica desatada desde el verano de ese año hasta nuestros días ha supuesto la destrucción de casi cuatro millones de puestos de trabajo ${ }^{3}$.

Tanto la elevada tasa de desempleo como sus fluctuaciones y la calidad del empleo creado han supuesto que, de forma lógica, se haya generado un debate político y social en relación a estos problemas, al que el campo académico no ha permanecido en absoluto indiferente con el desarrollo de múltiples investigaciones al respecto (algunos ejemplos serían Toharia, 1986; Pries, 1987; Míguélez y Prieto, 1999 y 2008; Polavieja, 2003; Koch, 2006; Prieto, 2009). Muchas de estas han indicado que la persistente tasa de desempleo estaría fuertemente influida numerosos problemas estructurales relacionados con factores como la industrialización tardía del país, el fordismo inacabado desarrollado durante el franquismo, la baja tasa de actividad y la todavía escasa incorporación de la mujer al trabajo, la inexistencia de una cultura que fomente la innovación y el emprendizaje, la falta de competencia en algunos mercados, etc. Más aún, la regulación del trabajo heredada del régimen franquista ha dejado una herencia problemática. El conocido Fuero del Trabajo, pieza esencial de las relaciones laborales del franquismo, pretendía establecer por ejemplo un modelo corporativo de inspiración fascista en un régimen autoritario. Desarrolló así una extensa regulación de los mercados laborales, particularmente en los mecanismos de salida

${ }^{3}$ El catastrófico dato de la EPA del cuarto trimestre de 2012 ha marcado un nuevo record negativo en la situación del empleo en España: 5.965.400 parados, nada menos que el $26,02 \%$ de la población. Los datos de la EPA citados en este artículo se encuentran disponibles en su totalidad en el Instituto Nacional de Estadística (www.ine.es). 
(dificultando el despido por causas no disciplinarias) y favoreciendo el modelo de contrato fijo como la norma de empleo básica (norma dirigida a un mercado de trabajo fundamentalmente masculino, mientras se empujaba a las mujeres al espacio doméstico) (Bilbao, 1993). Este sistema mantuvo unos niveles muy bajos tanto de tasa de actividad como de desempleo, si bien recurriendo a la emigración económica al norte de Europa de numerosos españoles con deseo y/o necesidad de trabajar al norte de Europa. Sin embargo, este modelo de relaciones industriales colapsó prácticamente a la vez que la dictadura, al ser la economía del país fuertemente golpeada por la Crisis del Petróleo. Ello forzó un proceso de fuerte reajuste interno de la economía española, que acompañó a una transición política peculiar, marcada por una creciente conflictividad laboral y social, un aumento sostenido del desempleo y de la inflación y el fin de la emigración como estrategia de ajuste laboral debido a la profunda crisis económica global del momento (Alonso, 2007).

A lo largo de la transición a la democracia se desarrollaron un conjunto de proyectos para intentar frenar el deterioro de la economía española a la vez que se buscaron acuerdos globales con el fin de garantizar la estabilidad política e institucional. Así, los Pactos de la Moncloa de diciembre de 1977 fueron suscritos por los partidos políticos, la patronal y algunos sindicatos, y supusieron la transformación de la economía española en un sistema de libre mercado con algunos aspectos sociales (la referencia a la intervención de los poderes públicos) y la consecución de una relativa estabilidad macroeconómica (la inflación se mantuvo bajo control poco después) (Fishman, 1996). Ese mismo año se habían legalizado tanto los sindicatos como las asociaciones empresariales, contribuyendo a la formación de un incipiente y aún frágil modelo de relaciones industriales (Martínez Lucio, 1990). Los primeros resultados de esas negociaciones estuvieron todavía fuertemente influidos por la inercia de la socialdemocracia europea, que paradójicamente comenzaba su crisis en Europa en ese mismo período. De este modo, tanto el Estatuto de los Trabajadores como el resto de leyes promulgadas durante esa época estaban construidas sobre el ideario de una ciudadanía laboral (Alonso, 2007). Sin embargo, la profundización de la crisis económica, el aumento constante de la tasa de desempleo (que alcanza el $20 \%$ a mediados de la década de los ochenta) y la nueva política económica desarrollada durante el gobierno del PSOE con el objetivo de incorporar al país a la CEE provocaron un fuerte cambio de rumbo en la orientación de las relaciones industriales en España a partir de 1984: la agenda de los empleadores termina imponiéndose sobre la de los sindicatos (Martínez Lucio, 1990). En este nuevo escenario se puso en marcha la primera reforma laboral, que introdujo una serie de medidas cuya estrella indiscutible era la instauración de los contratos de carácter temporal, en un contexto de fuerte reestructuración industrial cuyo fin no era otro que el de adaptar la economía española a un nuevo paradigma post-fordista y post-industrial (Alonso y Martínez Lucio, 2006). Desde entonces, las continuas reformas aprobadas a lo largo de las últimas tres décadas han estado justificadas en la necesidad de introducir más y más flexibilidad en un mercado laboral supuestamente muy rígido (Malo, 2005), lo que ha implicado que tanto los gobiernos del PSOE y del PP hayan terminado 
adoptando de forma clara la visión de las asociaciones empresariales. Las reformas en torno al despido se han caracterizado por afrontar cambios parciales, afectando al coste del despido a través de cambios en su diseño legislativo.

Esta continua referencia a la necesidad de introducir más flexibilidad se ha convertido en básicamente el discurso hegemónico en materia de relaciones laborales desde la década de los ochenta, reapareciendo con toda su crudeza en épocas de destrucción de empleo. El efecto de esta perspectiva sobre la regulación del mercado de trabajo español ha sido innegable, pues ha inspirado sin duda alguna las distintas reformas laborales aprobadas antes de la última crisis (1984, 1994, 1997 y 2006) cuyo objetivo confeso había sido el de configurar un mercado de trabajo más flexible, introduciendo no sólo una pléyade de contratos distintos al indefinido (de prácticas, por obra y servicio, etc.) sino además reduciendo de forma continuada los costes de despido (Zufiaur, 2009). Esto supuso que, pese al crecimiento económico del período 1995-2008 y la continua disminución de la tasa de desempleo, el mercado de trabajo español estuviera fuertemente marcado por la inestabilidad de las trayectorias laborales y una fuerte precariedad entre ciertos sectores de la población (jóvenes, inmigrantes y mujeres especialmente), al ser más de un tercio de los contratos existentes temporales (Miguélez y Prieto, 2009) y existir una apuesta por sectores económicos caracterizados por una baja productividad (FMI, 2010). Esta situación ha acrecentado las desigualdades sociales y económicas dentro del país, como han señalado numerosas investigaciones (DíazSalazar, 2003; Alonso y Fernández Rodríguez, 2008; Prieto, 2009).

No obstante, el impacto de la última crisis económica ha supuesto, como se había indicado anteriormente, un resurgir de los discursos a favor de la flexibilización del mercado laboral como medida esencial para la salida de la crisis. Una de las opiniones que más influencia ha tenido en la orientación de la lucha contra el desempleo ha sido la de un conjunto de académicos, fundamentalmente economistas vinculados a FEDEA (una fundación dedicada a la promoción de estudios económicos), que han sostenido en sus trabajos que la principal razón de la elevada tasa de desempleo española y la dificultad para crear nuevos empleos es la excesiva rigidez del mercado laboral español (excesiva regulación, altos costes de despido) que impiden un funcionamiento adecuado del mismo (Lamo y Dolado, 1993; Bentolila y Dolado, 1994; Costain, Gimeno y Thomas, 2010). Este grupo llegó a publicar, en enero de 2009, un manifiesto (el Manifiesto de los 100, 2009; ver también Dolado y Felgueroso, 2010) en el que reclamaban un nuevo tipo de contrato único con el que se resolvería el, en su opinión, principal problema: el marcado dualismo existente entre contratos con una elevada protección social, salarios altos y fuertes restricciones al despido (en forma de altos costes) y una pléyade de contratos precarios temporales con escasa protección social. Más allá de las críticas y limitaciones que su programa ofrece, lo cierto es que recoge de forma evidente una de las ideas que ha calado con más fuerza en los discursos hegemónicos en España en relación al problema del desempleo en España: el hecho de que existe un importante grupo de trabajadores que se encuentran excesivamente protegidos, siendo los trabajadores en condiciones más precarias los que pagarían, 
con sus despidos, los ajustes en el empleo propios de las crisis (ver Lindbeck y Snower, 1988; Toharia y Malo, 2000; Polavieja, 2003).

Este discurso ha sido asumido, con una serie de matices y en diversas formas, por las principales autoridades políticas del país desde la década de los ochenta, y se ha convertido en uno de los temas esenciales de la posición de la patronal española (recogida por la CEOE) desde entonces. Los representantes de las asociaciones de empresarios españoles han argumentado que la incapacidad de la economía española para crear nuevos empleos se debe, fundamentalmente, a que los costes asociados al despido de un trabajador son mucho más elevados en España que en el resto de la Unión Europea, lo que desmotivaría a empresarios y emprendedores a asumir riesgos en las contrataciones. Esta cuestión de los altos costes de despido se ha convertido, de hecho, en central en el debate y discusión sobre la reforma del sistema de relaciones laborales español, hasta el punto de erigirse en motivo de las mayores fricciones y desencuentros en el ámbito de las relaciones industriales españolas, particularmente en épocas de crisis. Así, durante los años 2009 y 2010 las negociaciones entre la CEOE (que había asumido una posición mucho más dura en las negociaciones bajo la dirección de su controvertido líder Gerardo Díaz Ferrán, en prisión por diversos cargos en la fecha en que escribimos estas líneas, y que mantiene en la actualidad) y las fuerzas sindicales se habían frenado por parte de los primeros hasta que el gobierno (entonces del PSOE) no asumiese una reforma laboral que contemplase una reducción de estos costes de despido (Europa Press, 2009; EFE, 2010a y 2010b). Instituciones como el FMI o la OCDE habían demandado asimismo importantes reformas en el mercado de trabajo español y, pese a reconocer en sus informes los notables problemas que existían en relación al sistema productivo, solicitaba la puesta en práctica de medidas destinadas a desmantelar las "rigideces" del mercado laboral e introducir más flexibilidad (FMI, 2008 y 2010).

Estas demandas se radicalizaron de manera sensible a partir del estallido de la crisis de la deuda europea y la degradación de la calificación crediticia española por parte de las agencias internacionales, con el consiguiente aumento de los costes de endeudamiento. Pese a que algunos autores han señalado que la crisis es más bien el resultado del agotamiento de un cierto modelo productivo (López y Rodríguez, 2010), el discurso de la rigidez del mercado de trabajo y de la necesidad de reducir los costes de despido se ha terminado imponiendo. La CEOE inició a partir de 2008 una auténtica ofensiva a favor de la necesidad de reformas laborales que permitan menores costes de contratación y despido, y más facilidades administrativas (particularmente para los Expedientes de Regulación de Empleo) pues de ello no sólo depende que la tasa de desempleo se reduzca, sino que se pueda mantener incluso la sostenibilidad de las pensiones (EFE, 2009a y 2009b). Al mismo tiempo, las ideas de FEDEA encontraron una gran difusión rápidamente tanto entre la prensa económica como general, y particularmente entre los responsables de la política económica nacional. Tanto CEOE como FEDEA han hecho hincapié en la necesidad de crear un contrato de tipo único (o "anti-crisis") que reduciría drásticamente los costes de despido (se llegó a hablar de 8 días por año trabajado 
durante los dos primeros años) que aumentarían con el tiempo en una cantidad que en ningún caso superaría los 20 días (Europa Press, 2009). Instituciones como el Banco de España centraron sus esfuerzos en demandar una reforma del mercado de trabajo (ver por ejemplo Fernández Ordóñez, 2008), poniendo en ello más esfuerzo que en analizar problemas de su competencia como el verdadero estado de las entidades financieras.

Todas estas presiones, junto a un contexto de desempleo creciente, ha provocado la puesta en marcha, por parte de los dos últimos gobiernos, no solamente de severas políticas de austeridad para atajar el desbocado déficit público fuertemente contestadas socialmente (en forma de recortes en el gasto público con reducciones en la inversión pública y en las prestaciones sociales, rebajas salariales a los empleados públicos, etc.), sino sobre todo tres reformas laborales en tres años consecutivos destinadas a realizar cambios en el modelo de relaciones laborales con un claro sesgo hacia los intereses de las asociaciones empresariales, con medidas tales como la descentralización de la negociación colectiva, la finalización de la obligación de hacer fijo a un trabajador que ha encadenado varios contratos temporales, reformas en la gestión del desempleo, mayores controles sobre el absentismo, etc. De manera peculiar, la medida "estrella" (y que ha tenido más impacto mediático) ha sido, de forma sistemática, la misma: reducir los costes de despido, expresados en días por año trabajado. Si la reforma de 2010 apostaba por generalizar la indemnización de 33 días anuales frente a los 45 que habían sido la norma en el modelo español hasta entonces, la reforma de 2012 ha ido más lejos apostando por los 20 días. Esta línea de actuación ha contado con una vigorosa oposición por parte de las fuerzas sindicales españolas, que denuncian que estas medidas están encaminadas a la consagración del despido libre y han respondido a las diferentes reformas laborales aprobadas durante la crisis con tres huelgas generales y numerosas manifestaciones de protesta.

Sin embargo, y pese a la introducción a partir de estas reformas de una mayor flexibilidad en el mercado de trabajo español, las demandas a favor de una mayor flexibilidad por parte de las asociaciones empresariales no han cesado. Han situado a la supuesta rigidez del mercado laboral como el principal problema que explica el desempleo en España, y conforme se han sucedido las crisis económicas en España, este discurso de la flexibilidad reaparece con más fuerza, forzando que el compromiso de la negociación colectiva se traslade al terreno de la reducción de los costes de despido y obligando a los actores sindicales a asumir posiciones defensivas. De este modo, es posible argumentar que a través de su desarrollo histórico, el discurso del despido libre ha sido esencial no solamente para poner en práctica reformas del mercado de trabajo, sino para condicionar por completo la agenda de las relaciones de empleo en España. Los costes del despido son vistos por los defensores del neoliberalismo como el último rompecabezas a resolver para terminar con el sistema de relaciones industriales de inspiración socialdemócrata. Para los representantes de las asociaciones empresariales (particularmente CEOE), es fundamental por tanto reducir los costes del despido, hasta el punto de que estos se reduzcan a cero o permitiendo nuevas modalidades de contratación, aportando 
ideas como los mencionados contratos anti-crisis o, más recientemente, la necesidad de generar los famosos mini-empleos que, de acuerdo con las posiciones empresariales (sobre todo del nuevo líder de la CEOE, Juan Rosell) tanto habrían ayudado a Alemania a sortear la crisis. Su posición, así, se podría sintetizar en los siguientes puntos:

a) En primer lugar, de acuerdo a la patronal, los despidos en España son muy caros en comparación a la media de la UE: si estos costes fueran menores, los empleadores no tendrían tantas reticencias a contratar y se podrían generar más empleos.

b) La forma en la que los despidos se encuentran regulados en la actualidad limita la autoridad del empleador en el centro de trabajo, pese a las reformas ya puestas en práctica (particularmente la de 2012).

c) Estos elevados costes que el empleador debe asumir suponen detraer inversión que podría ser utilizada para políticas de innovación y cambio organizacional.

d) Ello además restringe la posibilidad de una renovación en las plantillas, por cuanto los empleadores se muestran poco proclives a contratar a personal cuyo rendimiento laboral desconocen a priori.

e) La existencia de estos elevados costes tiene graves consecuencias sobre la fuerza de trabajo existente, por cuanto los grupos más débiles (jóvenes, mujeres) se ven relegados a contratos más precarios, lo que termina generando un mercado de trabajo segmentado y plagado de desigualdades. Además frena el desarrollo del trabajo a tiempo parcial, al convertir a los contratos temporales en la fórmula más atractiva para los empleadores, ya que les permite evitar compromisos engorrosos.

f) La reducción de los costes de despido introduciría más dinamismo y flexibilidad en la economía española, racionalizando el mercado de trabajo y mejorando la competitividad de las compañías.

De este modo, la cuestión de los costes de despido se ha convertido en un elemento central en el terreno de las relaciones industriales en España, hasta el punto de difuminar otros posibles debates, como el de la articulación de un nuevo sistema productivo. El discurso del despido libre ha sido abanderado por los neoliberales españoles como una posibilidad de extender la desregulación al mercado de trabajo. 


\section{La influencia del discurso del despido libre en las agendas de las relaciones industriales españolas}

La cuestión de la flexibilidad en el mercado de trabajo y el despido libre en España ha asumido, por tanto, una posición central en los debates tanto políticos como académicos en el país. Existe un importante número de intervenciones y propuestas en la materia, así como posiciones que compiten por hacer llegar su mensaje al público en general. Sin embargo, y este es el aspecto que deseamos recalcar en este trabajo, no se trata únicamente de una cuestión de rigidez o flexibilidad mayor o menor, dado que el grado de rigidez existente puede ser interpretado de formas muy distintas. Esto es, que el mercado de trabajo español sea más o menos rígido puede ser relevante, pero es más importante el hecho de que este tema se haya convertido en el centro del debate de las relaciones industriales españolas, por lo que ello implica.

Es imprescindible observar que, por ejemplo, el debate en sí mismo indica las limitaciones con las que son representados y comprendidos tanto los problemas del mercado de trabajo como los propios actores. Locke y Thelen (1995: 341) han argumentado que es necesario comprender la forma en la que los empleadores afrontan diferentes rigideces institucionales, al enfrentarse a contextos en los que operan diferentes actores sociales y agencias gubernamentales que enfatizan, a su vez, determinadas significaciones y valencias a ciertas cuestiones. De este modo, podemos sostener que los problemas existentes en el mercado de trabajo no son hechos aislados, sino que se encuentran vinculados a determinadas formas de analizar dichos problemas (una mirada determinada que los encorseta) y a modos particulares de regulación que condicionan su desarrollo en el tiempo. Esto es, el debate sobre el despido libre está condicionado políticamente y es capaz de crear imágenes y perspectivas que tienen efectos directos e indirectos sobre las políticas económicas y de empleo puestas en práctica. $\mathrm{Y}$ en efecto, el debate contiene una serie de efectos derivados que van a generar un efecto de cierre, el cual limitará ostensiblemente tanto las discusiones como la forma en que se estructurará el sistema de relaciones de empleo español. Podemos discernir tres dimensiones aparejadas a estos efectos: 1) la forma en que el debate condiciona las agendas de empleadores y sindicatos (particularmente los primeros), además de las posibilidades existentes en las negociaciones; 2) la construcción ideológica del sujeto "trabajador" en el mercado de trabajo español, en términos tanto de identidad como de lo que significa el trabajo; 3) y la influencia que este debate tiene sobre las agendas investigadoras existentes sobre el mercado de trabajo español. Los efectos no son siempre evidentes y son indirectos en muchos casos: sin embargo, estructuran la forma en la que se concibe qué significa flexibilidad laboral y la manera en la que el contexto en el que nos encontramos (en este caso, el español) la conceptualiza. Todo ello tiene además impactos concretos sobre la forma en que se toman las decisiones políticas y económicas.

Podemos comenzar señalando la forma en la que el debate sobre el despido libre ha contribuido para la formación de la identidad de un conjunto de organizaciones. 
En el caso de los empleadores, la preocupación por la cuestión de los despidos ha sido central para construir la vertiente más política del discurso tanto de las organizaciones como de sus líderes desde principios de la década de los ochenta (Martínez Lucio, 1991). Recordemos que en el caso español los intereses del empresariado como clase se encuentran profundamente fragmentados, con importantes divergencias entre firmas de capital nacional y las multinacionales, y entre pequeñas y grandes empresas (Martínez Lucio y Blyton, 1995), lo que ha supuesto un desafio importante de cara a la formación de una identidad común y una política consistente por parte de los empleadores (que cuentan además con importantes diferencias regionales en cuestiones como tradiciones o valores empresariales). Las trayectorias de clase de gestores y emprendedores han sido de lo más variopinta, y alcanzar posiciones comunes no ha sido sencillo. Por ejemplo, las visiones acerca del rol que debe jugar el Estado en la economía (en sus diversas formas, como por ejemplo subvencionando ciertas actividades productivas directa o indirectamente) o el grado de participación de los trabajadores distan mucho de ser unitarias. Además, y debido a la larga duración del régimen franquista, la clara y necesaria articulación entre los intereses de trabajo y capital a través de la negociación colectiva había sido reprimida, diferida o simplemente cedida a la regulación directa por parte del Estado. Las dificultades para alcanzar un consenso eran difíciles una vez que, tras el fallecimiento de Franco, numerosos empleadores permanecían afines a una perspectiva autoritaria en relación a las relaciones laborales, frente a posiciones más liberales de otros. Por otra parte, y tras una victoria electoral aplastante en 1982, el PSOE se acomodó rápidamente en posiciones de liberalismo económico que se encontraban en sintonía con el capital financiero, mientras acometía una dura política de reconversión industrial (Smith, 1998). En resumen, las diferencias existentes dentro del capitalismo español han repercutido negativamente en el desarrollo de un discurso unitario, modernizador y transparente.

Ante esta situación de fragmentación, es por ello plausible que ese proyecto común del "despido libre" y, de manera más amplia, "mercados de trabajo libres o desregulados" haya sido utilizado para construir una narrativa que contribuya a unificar estas posiciones divergentes. Esta causa común se ha convertido en el centro del imaginario ideológico de los empleadores, cohesionando su identidad de clase (Martínez Lucio, 1998). Sirve así como aglutinante de una patronal que, cuando uno atiende a otras características, aparece como bastante dispersa y poco vertebrada. Por lo tanto, este discurso es absoluta y totalmente esencial como generador de una posición unitaria detrás de su principal organización de representación (la CEOE). La petición de un despido más libre ha actuado, y actúa, como un discurso que sitúa a un "trabajador sin modernizar" y sus organizaciones afines (sindicales) como una barrera a la constitución de un moderno sistema de relaciones laborales, limitando la posibilidad de que los empleadores, representantes de lo novedoso y lo moderno, puedan operar con libertad y permitir la innovación organizacional. De este modo, el discurso de los empleadores españoles, en sintonía con los discursos gerenciales contemporáneos (Alonso y Fernández Rodríguez, 
2006; Fernández Rodríguez, 2007), se construye sobre una estrategia en la que integra, dentro de su visión evidentemente pro-capitalista, demandas de una mayor libertad personal y flexibilidad, junto a la eliminación de aquellas barreras que impiden al individuo ser libre (la burocracia, las reglamentaciones, las regulaciones, etc.). Se argumenta así que por ejemplo, los jóvenes ya no quieren tener un trabajo fijo, que los empleados actuales quieren crecer con las empresas pero que no pueden garantizar su fidelidad (por lo que deben competir por retener el talento), etc., en línea con las teorías gerenciales de gestión del talento (Scullion et al., 2007). De esta forma, una narrativa del trabajador inflexible emerge, en la que se plantea que los empleadores son agentes dinamizadores de la economía que se enfrentan a constricciones legales antediluvianas y formas de regulación colectiva obsoletas perjudiciales para su actividad. La cuestión del despido libre tiene, por tanto, implicaciones políticas relevantes, más aún cuando su extraordinaria fuerza a nivel ideológico y simbólico lo convierte en un discurso autónomo que pervierte la naturaleza de cualquier debate racional y serio sobre las reformas del mercado de trabajo. Se trata de un mantra que, con independencia de que responda a una situación real, distorsiona de hecho una posible discusión libre y sin límites previos. Se convierte en un topoi (lugar común) al que recurren los empleadores en cualquier situación con independencia de que se ajuste a la realidad.

Las centrales sindicales tampoco permanecen indiferentes a los contenidos de este discurso. Lo han contestado haciendo referencia al nivel extremo de flexibilidad en el mercado de trabajo, que se aprecia en la extrema destrucción de puestos de trabajo y el excesivo uso de contratos temporales en el mercado de trabajo español. Sin embargo, este debate fuerza a los sindicatos a mantenerse en una posición defensiva, pues su fuerza y capacidad de defensa de los intereses de los trabajadores es evaluada en términos de su habilidad para resistir las drásticas reformas del despido planteadas por los empleadores. Así, el debate se ha inclinado hacia la discusión de los costes del trabajo, el nivel de compensación justo tras la terminación del contrato de trabajo, y los derechos de los trabajadores a recibir una indemnización por despido. La cuestión del despido y la defensa de unos derechos de salida se perciben, por parte de algunos sindicalistas, como un examen de su verdadera fuerza y capacidad de movilización. Esto, por supuesto, puede someterse a interpretaciones diversas, aunque existe un consenso en que concesiones en esta materia van a estar sometidas a un estrecho escrutinio y pueden ser aprovechadas por los empleadores para ir más allá en su ofensiva desreguladora: ceder en este terreno conlleva elevados riesgos en términos políticos y de legitimidad organizacional. El diálogo social en España se extiende a numerosos ámbitos de las relaciones laborales, pero la aproximación a través de reformas crea dificultades e incrementa las percepciones de riesgo. De este modo, la ruptura del diálogo social entre sindicatos, gobierno y empleadores en los últimos años estuvo directamente vinculada a la puesta sobre la mesa de la cuestión de los costes del despido que suponían de alguna forma traspasar ciertas líneas rojas establecidas por los sindicatos, por lo que arrancar concesiones voluntarias de estos era muy difícil por los riesgos aparejados antes mencionados. Esto genera una situación de 
desconfianza ante las propuestas de la patronal por parte de los sindicatos, cuyo resultado final es el de reducir las posibilidades de debate e impedir la posibilidad de un diálogo más activo en el que pudieran discutirse otros aspectos del mercado de trabajo y sus posibles cambios. De este modo, en el modelo de relaciones laborales español encontramos algunos aspectos concretos que se ajustan a una idea de relaciones neo-corporativas como es el caso de la formación, aunque esta experiencia de diálogo social genuino no se ha trasladado a otras esferas como la cuestión de los costes del despido: se puede decir por ello que este tema contribuye, de manera clara, a la fragmentación del modelo (Martínez Lucio, 2008).

El impacto del debate sobre el despido libre debe ser visto por tanto en términos del modo en que condiciona las identidades y los puntos de vista de los actores institucionales. No obstante, no son esos los únicos aspectos en los que tiene influencia: también tiene efecto sobre la percepción existente acerca de los trabajadores y el trabajo en general. La salida del empleo se convierte en un tema central gracias a este discurso del despido libre, mientras otras esferas del trabajo reclutamiento, retención del trabajador dentro de la empresa, formación, etc.quedan relegadas a un segundo plano. Parece como si una cuestión muy limitada y concreta dentro de la trayectoria de los trabajadores en las empresas fuese la única relevante dentro de la amplia gama de cuestiones relacionadas con el desarrollo y gestión de los recursos humanos del país, hasta el punto de parecer la única cuestión susceptible de ser debatida en profundidad en el modelo de relaciones industriales del país, obviando la importancia indudable de otras cuestiones. El discurso sobre el despido libre -sobre todo en la forma en que es representado por la derecha política y una parte significativa de las asociaciones empresariales- tiene el efecto de presentar una economía española excesivamente regulada y con escasa innovación organizacional.

Dentro de esta presentación, se percibe una construcción ideológica del trabajador español: una imagen de un empleado poco comprometido e ineficiente, incapaz de comprender la necesidad de innovar y de ser productivo, y que se perpetúa, de manera lastimosa, dentro del modelo vigente en España de relaciones laborales. Un conjunto de actores (think tanks, asesores, políticos y periodistas de derechas) juegan un papel fundamental en esa descripción de la economía española como un espacio dañado por la falta de flexibilidad. Ello implica además una peculiar cosmovisión de los trabajadores en los que estos se sentirían ajenos al impulso de cambio e innovación debido a sus privilegiadas condiciones laborales (en forma de un contrato indefinido) que impiden que su empleador pueda acometer procesos de renovación organizacional ante los elevados costes económicos que ello supondría. Esto sirve - de una manera directa o indirecta- para construir una imagen del trabajador español como inmóvil, pasivo, lento y no interesado en el progreso, en un ejercicio de auténtico racismo de clase. Esta imagen tiene además resonancia internacional, contribuyendo a la construcción de un estereotipo racista (el trabajador de los PIGS, vago y que vive muy por encima de sus posibilidades) que ha jugado un papel importante en la puesta en práctica de medidas de austeridad. Se describe al trabajador como un sujeto aprovechado que, tras 
conseguir el trabajo fijo, deja de rendir en el centro de trabajo suficientemente: esta imagen es corroborada por amplios segmentos de la sociedad española, particularmente en la derecha del espectro ideológico. El despido libre sería, por tanto, un remedio para acabar con ese comportamiento inaceptable y mejorar la imagen del trabajador: sería una solución catártica que abriría nuevas posibilidades de cambio, reforma y mayor libertad. El impacto de este discurso es tal que deja fuera del foco las grandes dificultades que tiene el trabajador moderno de alcanzar cierta estabilidad en su empleo, ante las condiciones generadas en los mercados de trabajo desde hace varias décadas por la globalización financiera (Ibáñez Rojo y López Calle, 2012). De este modo, la imagen del empleado construida por el discurso del despido libre es la de una persona poco solidaria y poco trabajadora que sólo mira por sus intereses; personas despreocupadas por la calidad de su trabajo que únicamente intentan mantener su puesto a toda costa. Esto encaja bien dentro del imaginario ideológico de la derecha española, que ha juzgado tradicionalmente al trabajador español como alguien taimado y no digno de confianza: en este sentido, los españoles como pueblo son un grupo desorganizado, individualista y difícil de gobernar, por lo que requerirían disciplina y control (Caro Baroja, 2004). Los anárquicos empleados españoles sólo pueden ser controlados adecuadamente mediante mecanismos disciplinarios poderosos: en otra época fue el Estado autoritario, en la actualidad la implacable "mano invisible" del mercado.

Esto deja la puerta abierta a una visión del despido libre como un posible acto social de justicia, que permite de alguna forma "igualar" el acceso al empleo entre aquellos que han tenido una trayectoria privilegiada y el resto que no ha contado con las mismas posibilidades por razones generacionales o formas diversas de discriminación (los jóvenes por ejemplo) ${ }^{4}$. El empleado español egoísta y poco innovador sería, así, más bien un trabajador maduro, corrompido por su exceso de estabilidad en el trabajo: esta estrategia discursiva permite que sea presentado, metafóricamente, como alguien del pasado, una rémora frente a los empleados JASP, jóvenes aunque sobradamente preparados, hambrientos de cambio, innovación y búsqueda de mayor productividad. Este elemento en la narrativa del empleado contribuye negativamente a generar una mayor fragmentación en las identidades de los trabajadores, por cuanto incitan al desgaste de las relaciones de

${ }^{4}$ Existe un debate similar en Francia en relación a esta cuestión: así, algunos economistas están advirtiendo de los peligros que ha supuesto y supone proteger a un sector determinado de los trabajadores (aquellos que por su sector o generación han tenido acceso al denominado "estatuto", esto es, una serie de derechos laborales y privilegios específicos), pues ello termina creando rigidez, dualismos e injusticias en el mercado laboral, ya que no todos los trabajadores tienen acceso a dicho estatuto. Ello contribuiría además, según estos economistas, a la generalización de una sensación de angustia y miedo en toda la sociedad (ver Maurin, 2009). 
confianza entre distintas generaciones e impone la dinámica del mecanismo disciplinario (el despido libre actuaría como auténtico dispositivo foucaultiano) como correctora de los problemas del mercado de trabajo.

La persistencia de estas imágenes del trabajo en España -un enfermo en el imaginario europeo, debido a sus elevados datos estructurales de paro- continúa perpetuándose en ciertos círculos políticos y mediáticos, con independencia de los ciclos económicos y del desarrollo de una imagen innovadora y moderna del país la conocida "marca España", hoy en crisis. En muchos artículos académicos, España es presentada como un espacio donde el factor contextual fundamental en la actividad económica son los costes del trabajo, y donde el mercado de trabajo simplemente no funciona. Ello contribuye a distorsionar la imagen del trabajo en España al asociarlo a esa única dimensión de inflexibilidad -que ni siquiera es correcta, dada la elevada flexibilidad numérica y la elevada tasa de sustitución de personal en determinadas empresas. Conduce, de este modo, a reforzar la imagen de un país mal gestionado y necesitado de grandes reformas -una suerte de "nueva leyenda negra" en la que empleados perezosos y egoístas deben convertirse en flexibles para ajustarse a los requerimientos de una economía del conocimiento 5 .

Esta cuestión es relevante. El elevado desempleo de España - uno de los más altos de Europa desde la década de los ochenta- no se justifica en el desarrollo peculiar de la economía española, la escasa presencia de sectores con una cierta estabilidad, las desigualdades de género del mercado de trabajo u otros posibles factores, sino que se atribuye de manera particular a la imposibilidad de despedir a los empleados, algo que, si se corrigiese, permitiría a los empleadores contratar a más personal y asumir mayores riesgos en términos de empleo (al ser los costes más

\footnotetext{
${ }^{5}$ Esta "leyenda negra" sobre la economía española se ha reforzado considerablemente durante esta época de crisis. Desde finales de 2008, periódicos económicos internacionales bien conocidos como Te Economista, Newsweek o Financials Times han publicado duros artículos en relación a los problemas estructurales de la economía española, sus compañías de referencia y su fuerza de trabajo. De este modo, hemos pasado del 'Smiling Spain' de finales de los noventa (donde se elogiaba el primer mandato de Aznar como el de la modernización definitive, al contra con un gobierno que por fin había disciplinado las finanzas públicas de acuerdo a los criterios de Maastricht y que por tanto había alcanzado con todo merecimiento el honor de unirse a la zona euro), a en la actualidad formar parte del selecto grupo de los PIGS, países señalados en su momento por sus retrasos estructurales, su falta de competitividad internacional en los sectores con mayor valor añadido y su debilidad económica para afrontar el contexto de crisis (y cuyos ciudadanos fueron señalados, en un discurso obviamente cargado de tintes racistas, como perezosos y excesivamente acomodados), y que, posteriormente, uno a uno han sido rescatados por préstamos de la llamada troika para evitar la bancarrota. Estas imágenes y acrónimos de signo tan peyorativo confirman la persistencia de estas imágenes estereotipadas sobre España, reforzadas de alguna manera por este discurso del despido libre que estamos discutiendo aquí.
} 
bajos). La relación que se establece en términos discursivos entre salida del empleo y desempleo contribuye para construir una imagen de los sindicatos en los que estos son meros defensores de intereses creados y los trabajadores individuos incapaces de articular una visión más amplia de la necesidad de cambio y la renovación. De este modo, se transfiere la responsabilidad del elevado desempleo al trabajador, tanto a nivel individual como colectivo, y al legado de regulación heredado del franquismo como si tal régimen de relaciones laborales no hubiera sido profundamente lesivo de los intereses de los trabajadores. El sistema de relaciones industriales se categorizará, en este discurso, como un régimen disfuncional pese a su evolución e innovaciones a lo largo del período democrático, culpándose a los trabajadores de haberse quedado encapsulados en una situación anterior y por ello defender aspectos de un régimen laboral autoritario y desfasado. De este modo, en el discurso del despido libre, los empleadores terminan representados como víctimas de una legislación heredada del franquismo, a pesar de que en el régimen anterior trabajaron interesadamente y codo con codo con la dictadura para reprimir los derechos laborales y sindicales de aquellos que demandaban libertad.

Por lo tanto, la cuestión del despido libre como una característica fundamental de la narrativa establecida en España en relación a las relaciones laborales es, por tanto, extraordinariamente influyente y configura de manera acusada posiciones y agendas $-\mathrm{y}$ eso sin contar la forma en la que sirve para revisar la historia, como acabamos de leer. Este ejercicio de story-telling sirve para establecer una metáfora del fracaso de las relaciones de confianza entre los distintos agentes del mundo económico -capital y trabajo-, colocándolos en una relación de sospecha mutua pese a una larga serie de acuerdos a lo largo de la democracia. Influye además, de forma muy poderosa, en la forma en que este debate se discute en el mundo académico. En este espacio, sociólogos y economistas pretenden mostrar hasta qué punto los costes de despido impiden crear empleo y crecer económicamente y si estos costes inciden en que se recurra a contratos temporales o no. Durante 2009, una serie de manifiestos y contra-manifiestos fueron promulgados por diferentes grupos de académicos defendiendo sus posturas de forma apasionada. El Manifiesto de los 700 (redactado para contrarrestar la extraordinaria notoriedad que alcanzó el Manifiesto de los 100, que defendía la rebaja de los costes de despido) argumentaba que:

"No es promoviendo el despido sin causa ni control judicial, como se avanza hacia un mercado laboral en el contexto de un nuevo modelo económico más productivo. La pretendida simplificación en el régimen de la contratación terminaría haciendo aflorar su verdadero propósito: la simplificación del régimen de despido. Ya no habría, salvo en limitadísimas ocasiones, despidos procedentes ni improcedentes; el resultado sería la precariedad generalizada de los trabajadores y el abaratamiento del despido.

Por tanto si resulta unánime la opinión de la inexistencia de conexiones entre la actual crisis económica y la regulación del mercado de trabajo, no es en modo alguno congruente querer aprovechar la presente situación para reducir o 
eliminar derechos sociales. O en palabras más enérgicas, nos parece políticamente indecente pretender desplazar a los trabajadores una parte sustancial de los costes de la crisis económica" (Manifiesto de los 700, 2009: 482-483).

Según este grupo de académicos, era importante promover medidas que hicieran frente a la crisis, pero esas medidas no debían ser dirigidas hacia nuevas reformas del mercado de trabajo. Demandaban políticas que contribuyesen a la formación de un nuevo modelo productivo basado en la innovación y en actividades de alto valor añadido, tomando la centralidad del trabajo en la estructura económica como condición necesaria $\mathrm{Ni}$ que decir tiene que no fueron escuchados.

Desde una perspectiva neoliberal ortodoxa, este debate sobre el despido libre contiene notables paralelismos con la americanización de los recursos humanos y el problema persistente del compromiso de los trabajadores, que nunca parece ser suficiente (Rodríguez Ruiz y Martínez Lucio, 2010). Dentro de la economía, ha estimulado además un giro cuantitativo en el estudio del empleo a expensas de un sector minoritario todavía dedicado al análisis de la calidad del empleo. Este énfasis en los mecanismos de salida opera como una restricción que estrecha los posibles debates y preocupaciones en relación al empleo en España, dejando muchas cuestiones en la periferia de las discusiones que quedan sin responder, investigar ni analizar. De este modo, temas como la formación, la salud en el trabajo y los riesgos laborales se convierten en marginales o minoritarios en los departamentos de economía, e incluso algunos de derecho o relaciones industriales, salvo notables excepciones.

\section{Un discurso sobre el empleo de una economía liberal}

Una vez que hemos analizado el discurso del despido libre en España, es importante contextualizarlo en el escenario de las relaciones industriales españolas no solamente por sus implicaciones sino para comprender qué fines políticos persigue. En nuestra opinión, las asociaciones de empleadores han abrazado de forma ferviente una perspectiva neoliberal de las relaciones industriales, contemplando estas últimas como una amenaza a su autoridad legítima en su gestión de los recursos humanos. Es importante resaltar que la referencia que hacen a la rigidez y excesiva regulación de tales relaciones está muy alejada de la realidad. El sistema de relaciones laborales español es considerablemente más débil que en países con una tradición socialdemócrata, y la cultura de consenso y acuerdos está significativamente menos desarrollada (sobre todo por razones históricas, como la larga dictadura). La realidad de la extensión de la regulación contrasta de manera notable con lo sostenido por los discursos: de hecho, casi todos los acuerdos han tenido un carácter temporal y estratégico y rara vez se han materializado en pactos permanentes y reales. De igual modo, y pese a lo sostenido desde estas posiciones neoliberales, los sindicatos y el sistema de relaciones industriales no han sido tan poderosos a la hora de poner trabas a la actividad empresarial, una vez que se 
observan las dificultades de implementar los acuerdos colectivos y de ampliar el contenido de los mismos, lo que prueba la capacidad limitada de regular que tienen los representantes del factor trabajo (Martínez Lucio, 2008).

La importancia simbólica que tiene esta cuestión de los costes del despido es el resultado de un compromiso con las clases trabajadoras en la transición hacia la democracia -la necesidad de introducir estabilidad en las relaciones de empleo mientras se constituía el propio sistema de relaciones industriales (Alonso, 2007). Esta regulación era parte de un acuerdo político implícito entre las clases medias y las trabajadoras a la hora de establecer una sociedad democrática con una economía social de mercado (Rodríguez Cabrero, 2009). Significaba además un elemento de seguridad en un contexto marcado por un desempleo muy elevado, y una extraordinaria incertidumbre acerca del futuro de toda una generación. Todo esto ha sido por supuesto ignorado en la mayoría de los documentos de apoyo al neoliberalismo, cuyos defensores pretenden silenciar el contenido de esos acuerdos implícitos de la transición política a la democracia.

Por otra parte, y si nos centramos en el extraordinario crecimiento del desempleo en España, una cuestión fundamental surge: ¿es tan difícil despedir en España? En 2009 se despidió a casi dos millones de personas, y tras la puesta en práctica de la reforma laboral de 2012 (que reducía los costes de despido de manera muy significativa y que serviría, según sus muñidores, para que las empresas españolas volviesen a crear empleo), ha descendido el número de ocupados en 850.000 personas con más de 670.000 despidos. El número de Expedientes de Regulación de Empleo (ERE) se ha multiplicado durante la crisis, contribuyendo a una destrucción masiva de empleo que, a fecha de hoy, ha llevado a España a liderar el ranking europeo con seis millones de desempleados. Existen además factores específicos que muestran tendencias peculiares de la gestión de recursos humanos en España. Así, la estrategia de los empleadores parece concentrarse más en el despido de los trabajadores que en otras actividades como la inversión en $\mathrm{I}+\mathrm{D}$ o en formación. Implica una visión de la flexibilidad muy particular, basada exclusivamente en los beneficios a corto plazo, y desdeñando inversiones a largo plazo en la fuerza de trabajo (Prieto, 2009). Finalmente, la extensión de la flexibilidad en España es muy elevada en términos de flexibilidad numérica (Miguélez y Prieto, 2008), lo que implica que la legislación existente sobre despidos no afecta realmente el desarrollo de mercados duales y del uso extensivo de la contratación de trabajadores temporales. Además, recurrir a contratación temporal de forma masiva no sirvió para, en situaciones de crisis, liderar las estadísticas europeas de desempleo.

Con independencia de la posición de cada uno en este debate, la actual perspectiva neoliberal en relación al mercado de trabajo debe ser engarzada dentro de la forma en que tal discurso político se ha configurado en España. Forma parte de un proyecto ideológico de los empleadores de sesgo derechista (Martínez Lucio, 2002) que tiene como objetivo añadir una dimensión de corte más anglosajón al sistema de relaciones industriales español y a sus procesos económicos, siendo en la actualidad un referente en el debate político nacional (con Esperanza Aguirre como figura más visible). Este proyecto neoliberal se inspira en diversos temas para 
articular una defensa del modelo liberal de relaciones industriales. Uno de los hechos más destacados en este sentido ha sido la emergencia de un nuevo lobby en la derecha española situado en las posiciones más conservadoras del PP, que ha contribuido a generar un nuevo discurso político. Este recuerda, en ocasiones, a la corriente de extrema derecha del Tea Party norteamericano, y goza de una notable influencia gracias a una potente comunicación mediática (a través de canales de televisión, periódicos y think tanks). En el discurso que difunden sus medios de comunicación, hay una obsesión en demonizar el "despilfarro de lo público", los "privilegios" de los funcionarios y, sobre todo, a los sindicatos, lo que ha servido para reforzar las posturas antisindicales que nutren el debate sobre el despido libre y las políticas anti-obreras.

En primer lugar, se atribuye a unos mercados libres y desregulados el alto índice de creación de empleo que tienen las economías británica y estadounidense. Así, Reino Unido ha sido capaz de crear una multitud de empleos en sectores postindustriales diversos, lo que ha contribuido a una vital reducción del desempleo. El dinamismo de estas economías se asocia, en ciertos círculos, a la emergencia de aproximaciones más cercanas a los intereses del mercado. Este interés en la posibilidad de crear actividades de alto valor añadido en un contexto de relaciones laborales desreguladas ha contribuido a formar un estado de opinión que ha calado de forma profunda en el discurso de la renovación del tejido productivo español tras la llegada de la democracia, con el reclamo de las nuevas tecnologías como justificación de la reconversión industrial. La transición política de los setenta y primeros ochenta, basada en la institucionalización de la democracia y la descentralización pronto fue suplantada por una transición económica en la que los mercados han condicionado todo aquello relacionado con lo social. Esto era evidente, de forma muy notable, en la forma en la que el crecimiento económico era conceptualizado en los discursos del gobierno de Felipe González en las décadas de los ochenta y noventa en términos de del mercado y el reto de ser mas integrados en un mercado liberal. WR Smith (1998) señaló cómo la línea política de González y Mitterrand dieron un giro conservador debido a la influencia de las políticas de privatización y desregulación promovidas por Margaret Thatcher. La izquierda de la década de los ochenta justificó limitar la relación con los sindicatos como eje fundamental de una política que garantizara el progreso económico y social.

En segundo lugar, este discurso hace un énfasis en permanecer, en términos de regulación, en un nivel de mínimos. Este giro neoliberal a la española celebra el hecho de que en los países anglosajones el Estado (particularmente en su vertiente de Bienestar, pero también de regulación) es contemplado como una institución que juega un mínimo papel en la economía, y que proporciona a sus ciudadanos unos mínimos de cobertura social, frente a la cobertura más ambiciosa de los países nórdicos. En este sentido, podemos encontrar una curiosa sinergia en la forma en que los gobiernos británicos desde 1979 (sean de inspiración thatcherista o sean laboristas que sigan los principios de la Tercera Vía) y españoles desde 1982 (sean socialdemócratas o conservadores) han desarrollado su política socioeconómica, con énfasis en la fiabilidad de los mercados, la descentralización y subcontratación 
de servicios a instituciones privadas y la colaboración permanente entre Estado y empresas. La influencia del modelo británico sobre el español (en forma de políticas como las privatizaciones o la transferencia de la gestión de centros públicos a empresas privadas) ha sido constante, contribuyendo a reforzar la idea de que el Estado, más que un proveedor de servicios, debe ser un intermediario que los adquiere en el mercado privado.

En tercer lugar, el discurso neoliberal desarrolla en profundidad un tema fundamental: la importancia en la economía de la figura del directivo-héroe (hero manager), ese gestor genial que, de cara a crear valor para sus accionistas y su empresa, debe enfrentarse al menor número de restricciones posibles a su actividad, que no es otra que la toma de decisiones (Fernández Rodríguez, 2007). La apertura de la economía española a la inversión extranjera y el crecimiento económico alcanzado en la segunda mitad de los ochenta tras la adhesión a la UE contribuyó a la expansión de nuevas ideologías gerenciales, procedentes sobre todo de EEUU. Muchos de esto discursos manageriales, difundidos de manera conjunta por las escuelas de negocios, la prensa económica o las grandes empresas, enfatizaban la importancia de un liderazgo fuerte dentro de las compañías españolas (Fernández Rodríguez y Gantman, 2011). Estos nuevos líderes, auténticos directivos-héroe, se convertirían en el modelo social a seguir: alguien extremadamente dinámico e intuitivo cuya visión, valores y gestión conducirían a las empresas hasta alcanzar el éxito y beneficios espectaculares. Este liderazgo carismático intentará comprometer a sus empleados, otorgándoles más responsabilidades para que innoven y sean capaces de crear valor para su empresa. En estos discursos se enfatiza mucho esta llamada a la libertad, a la vez que se demanda la desaparición de cualquier barrera que pueda comprometer el ejercicio de esas decisiones "libres": de este modo, la burocracia, los sindicatos o cualquier tipo de acción colectiva serán despreciados y considerados una amenaza a una gestión empresarial eficaz (Fernández Rodríguez, 2007; Du Gay, 2012). Se celebra la figura del emprendedor libre y se hace hincapié en los beneficios que los mercados van a traer a una España liberal y "postautoritaria" - en la que el aspecto del despido libre jugará un papel importante, ya que escenifica de alguna manera esa transformación de la sociedad y se ajusta a ese discurso de la flexibilidad y el cambio. El objetivo es de alguna manera exorcizar el legado anterior, al que se atribuyen obsesiones burocráticas inmemoriales ( $\mathrm{y}$ en el que se obvia la colusión de intereses públicos y privados que han caracterizado el devenir de la economía española desde el franquismo: ver López y Rodríguez, 2010), para incorporar a la economía española a ese nuevo lenguaje del cambio y la libertad. Para desarrollar este proyecto, se asistirá a la emergencia de nuevas redes formadas por prensa, consultoras e individuos clave tanto en el espectro político de la derecha como del centro (entendiendo aquí al sector más liberal del PSOE) que van a ejercer de auténtico lobby para conseguir desarrollar nuevas reformas en el mercado de trabajo, con una especial atención en la cuestión de los costes del despido. El neoliberalismo habría articulado (en el sentido de Laclau y Mouffe, 1984) una visión del mercado de trabajo basada en términos de elección individual (no es casual esa predilección de los gobiernos españoles por intelectuales cercanos 
a la teoría del actor racional) y discrecionalidad en la gestión - siendo el management la única vacuna posible ante la atávica inacción española.

Desde esta perspectiva y desde diversos frentes, asistimos a la consolidación de las escuelas de negocios como un espacio institucional fundamental desde el que se generará una nueva élite gestora que se ocupará de gestionar un futuro más allá de la acción colectiva, el bienestar y el Estado-nación. El culto a la flexibilidad coincidirá con ese giro de la derecha (y parte de la izquierda) española al neoliberalismo de inspiración anglosajona, donde el Estado se convierte en un Estado de mínimos y la cultura organizacional debe cambiar para asumir los principios del gerencialismo post-moderno. En este contexto, la "libertad" en el "despido libre" adquiere un significado concreto: supone permitir a la dirección de las empresas gozar de la discrecionalidad máxima en sus políticas de personal. Se trata de una nueva cruzada, no muy distinta a la que tuvo lugar en 1936 en la que los trabajadores -colectivamente- habían infestado las instituciones españolas y suponían una amenaza para el progreso económico. El uso peculiar, en la actualidad, del término "libre" dentro del concepto de "despido libre" recuerda a ese axioma anterior, manejado entonces por la extrema derecha y que asociaba libertad a unidad y fuerza. $Y$ en efecto, el término de alguna manera encubre los costes económicos y sociales de dicho tipo de despidos al asociar los contratos de trabajo y sus derechos asociados a las ideas de rigidez y empecinamiento en mantener cosas del pasado. Esta dimensión ideológica, es por tanto, un tema que merece una investigación en profundidad.

\section{Conclusiones}

La cuestión del despido libre contiene, por tanto, elementos y detalles relevantes que confirman la importancia del contexto a la hora de valorar reformas en este sentido. Es importante prestar atención a las estrategias de los distintos actores sociales (tanto élites como movimientos sociales) y a la forma en que ideas hegemónicas se han construido sobre marcos históricos e institucionales muy particulares, en los que se entrecruzan importantes tensiones económicas y sociales (Laclau y Mouffe, 1984; Hall, 1988). Particularmente, los factores históricos han sido fundamentales en el caso español, por cuanto las ideas neoliberales vigentes realizan una curiosa lectura del desarrollo del marco de relaciones laborales españolas, interpretando los problemas estructurales a partir de estrategias argumentativas que no pueden comprenderse sin analizar los problemas heredados y los contenidos de estas narrativas. La manipulación ideológica expresada en los discursos es, en este sentido, fundamental (Fairclough, 1995). Además, la construcción de un bloque hegemónico (en el sentido de Gramsci) a partir de una serie de alianzas de grupos y clases sociales pueden derivar en la construcción de una visión de país, de economía y de sociedad muy concreta, cuyos contenidos variarán en función de cómo se planteen alternativas y desafíos por parte de otros actores políticos, que denuncien las contradicciones de los discursos dominantes de 
forma exitosa. La ausencia de desafíos que puedan amenazar el orden existente $-\mathrm{O}$ la forma en que el discurso dominante desacredite esas alternativas, como sucede en el caso del despido libre con los sindicatos españoles, representados como defensores de un mecanismo desfasado en el tiempo, generador de segmentación laboral e injusto- puede contribuir de forma decisiva a que el discurso dominante se construya en forma de "sentido común" y única alternativa viable ${ }^{6}$. El desarrollo de "comparaciones selectivas" (por ejemplo, la referencia más reciente de los minijobs y la desregulación laboral como factor de éxito de la economía alemana) es una pieza fundamental en el entramado de esta estrategia de búsqueda de legitimidad (Martínez Lucio, 2002).

Por lo tanto, el debate sobre la flexibilidad en el mercado de trabajo español representa de manera precisa cómo un factor contextual puede emerger y transformarse súbitamente en el centro de la agenda política y de los procesos de reforma. Sirve para mostrarnos cómo las "enfermedades" de un modelo y los "desafíos" a los que nos enfrentamos pueden transformarse en mitologías (Fernández Rodríguez, 2007) que invaden el debate económico y político. De esta forma, toda discusión sobre el mercado de trabajo termina condicionado por estos factores, sus consecuencias sobre el entorno socioeconómico y sobre todo por una forma de enfocar el análisis de los problemas que desdeña las complejidades de la realidad laboral española. Así, esa imagen construida de trabajadores a los que no es posible despedir ha alcanzado tal estatus en el imaginario laboral español que ello termina contribuyendo a que el debate intelectual en relación a la naturaleza del trabajo, la calidad del empleo o la realidad de la flexibilidad contractual quede marginado y difuminado. Pese a los esfuerzos de proponer un debate serio sobre la estructura del modelo productivo, la participación en el centro de trabajo, la formación o la mejora de la calidad, la irresistible y poderosa metáfora de los costes de despido termina ocupando el centro de la agenda de las relaciones industriales, dejando estas cuestiones fundamentales fuera del debate. El discurso del despido libre ha contribuido a profundizar en estereotipos españoles que señalan al empleado como sujeto acomodaticio, poco trabajador e improductivo que es imprescindible disciplinar. Estas representaciones tienen la capacidad de cimentar un contexto muy particular dentro de la política pública, que limita considerablemente la capacidad de diálogo: la cuestión es ahora conocer cómo esto va a impactar a largo plazo sobre las decisiones en el terreno de las relaciones industriales. Hasta ahora, el legado de este discurso desde la década de los ochenta ha sido el de crear limitaciones y tensiones en el diálogo social, siendo la

\footnotetext{
${ }^{6}$ Recordemos la fuerza del sentido común en la argumentación cotidiana: para salir de la crisis existen incluso gurús y líderes políticos que nos recomiendan simplemente recurrir al sentido común como estrategia de superación de todos los problemas y adversidades: ver por ejemplo Abadía (2010) o el mismísimo Rajoy (2011).
} 
herramienta a la que han recurrido los diferentes gobiernos para politizar y manipular la política del mercado de trabajo.

Estas son cuestiones que, desde la perspectiva de la sociología y las relaciones industriales, merece la pena explorar, por cuanto sirven para configurar decisiones respecto a qué hacer y políticas concretas. En el Reino Unido, por ejemplo, la construcción de un debate acerca de la "cuestión del trabajador británico" durante las décadas de los sesenta y setenta culminó con una fuerte reacción por parte de la Nueva Derecha thatcherista que respondió no sólo a supuestos imperativos económicos, sino también políticos (Hall, 1988; Harvey, 2007). Cada vez más, si deseamos comprender la construcción y desarrollo de los sistemas de relaciones laborales, deberemos centrar nuestra atención no solamente en las comparaciones contextuales a las que hacen alusión Locke y Thelen (1995), sino además tener en cuenta las obsesiones, metáforas y disrupciones discursivas que influyen en nuestra comprensión o incomprensión de los contextos nacionales. Estas contribuirán a configurar un marco cognitivo dentro del cual no solamente se elaborarán representaciones de la realidad muy particulares y se tomarán decisiones, sino que además nos proporcionará una referencia de lo que significa el trabajo y las relaciones laborales para nosotros. En función de qué valor otorguemos a esos significados, las cosas se harán, socialmente, mejor o peor.

\section{Bibliografía}

Abadía, L. (2010). La hora de los sensatos. Una solución práctica a todos los problemas que nos ha traído la crisis. Barcelona: Espasa.

Alonso, L.E. (2007). La crisis de la ciudadanía laboral. Barcelona: Anthropos.

Alonso L.E., Fernández Rodríguez C.J. (2006). El imaginario managerial: el discurso de la fluidez en la sociedad económica. Política y Sociedad Vol. 43, $n^{\circ}$ 2, 127-151.

Alonso L.E., Fernández Rodríguez, C.J. (2008). Emploi et précarité des jeunes: le cas de l'Espagne. Travail et Emploi, Vol. 115, 71-80.

Alonso L.E., Martínez Lucio M. (eds.) (2006). Employment Relations in a Changing Society: Assessing the Post-Fordist Paradigm. Basingstoke: Palgrave Macmillan.

Amable, B. (2003). The Diversity of Modern Capitalism. Nueva York: OUP.

Aragón Medina, J., Lezcano, F. (2011). Crisis económica, crisis de la política y crisis del modelo: notas sobre las políticas para una salida social de la crisis. $\mathrm{Ga}$ ceta Sindical: reflexión y debate. Vol. 17, 11-25. 
Baylos, A. P. (2003). Las relaciones laborales en España desde la Constitución hasta nuestros días (1978-2003). Madrid: GPS-Madrid.

Bentolila S., Dolado J.J. (1994). Labour flexibility and wages: Lessons from Spain. Economic Policy. Vol. 9, $n^{\circ}$ 18, 52-99.

Bilbao, A. (1993). El contexto histórico de las ordenanzas laborales. Economía y sociología del trabajo. Vol. 21-22, 62-71.

Bilbao, A, (1999), El empleo precario: seguridad de la economía e inseguridad del trabajo. Madrid: La Catarata.

Blyton, P., Martínez Lucio, M. (1995). Industrial relations and the management of flexibility: A comparison of Britain and Spain. International Journal of Human Resource Management. Vol. 6, $n^{\circ}$ 2, 271-292.

Boyer, R. (1988). The Search for Labour Market Flexibility. Oxford: OUP.

Caro Baroja, J. (2004). El mito del carácter nacional y su formación con respecto a España. Madrid: Caro Raggio.

Coates, D. (2000). Models of Capitalism. Cambridge: Polity Press.

Costain J, Gimeno JF, Thomas, C. (2010). Fluctuaciones del empleo en un mercado de trabajo con contratación dual. Disponible en: http://www.bde.es/webbde/SES/Secciones/Publicaciones/InformesBoletinesRevi stas/BoletinEconomico/10/Mar/Fich/art3.pdf (consultado el 26/02/2013).

Díaz-Salazar, R (2003). Trabajadores precarios: el proletariado del siglo XXI. Madrid: HOAC.

Dolado, J., Felgueroso, F. (eds) (2010). Propuesta para la reactivación laboral en España. Disponible en: http://www.crisis09.es/propuesta/?page_id=755 (consultado el 26/02/2013).

Du Gay, P. (2012). En elogio de la burocracia: Weber, organización, ética. Madrid: Siglo XXI.

EFE (2009a). Díaz Ferrán cree que la Administración no debería autorizar los ERE para que fueran más rápidos. La Voz de Galicia 17 de febrero. Disponible en: http://www.lavozdegalicia.es/dinero/2009/02/17/00031234869073100152536.ht m?utm_source=buscavoz\&utm_medium=buscavoz (consultado el 11/02/2013). 
EFE (2009b). Díaz Ferrán cree que peligrarán las pensiones si no hay reforma laboral. Cinco Días. Disponible en: $\mathrm{http} / / / \mathrm{www}$.cincodias.com/articulo/economia/diaz-ferran-cree-peligraranpensiones-hay-reforma-laboral/20090423cdscdseco_24/ (consultado el 13/01/2013).

EFE (2010a). La CEOE achaca a los salarios y al coste del despido la destrucción de empleo. La Vanguardia 19 de enero. Disponible en:

$\mathrm{http}: / / \mathrm{www}$.lavanguardia.es/economia/fiscalidadempresa/20100119/53873680185/la-ceoe-achaca-a-los-salarios-y-al-coste-deldespido-la-destruccion-de-empleo.html (consultado el 11/02/2013).

EFE (2010b). El Gobierno generaliza el contrato con 33 días de indemnización. El País 16 de junio. Disponible en:

http://www.elpais.com/articulo/economia/Gobierno/generaliza/contrato/33/dias/i ndemnizacion/elpepueco/20100616elpepueco_10/Tes (consultado el 02/03/2013).

Europa Press (2009). La CEOE propone un contrato de crisis con una indemnización de ocho días por año. Cinco Días 22 de abril. Disponible en: http://www.cincodias.com/articulo/economia/CEOE-propone-contrato-crisisindemnizacion-dias-ano/20090422cdscdseco_32/ (consultado el 02/03/2013).

Fairclough, N. (1989). Language and Power. Londres: Longman.

Fairclough, N. (1995). Critical Discourse Analysis. Londres: Longman.

Fernández Ordóñez, M.A. (2008) Discurso de apertura del Seminario de alto nivel sobre experiencias en el mercado laboral: hacia mercados de trabajo eficientes/FMI-Banco de España. Disponible en:

http://www.bde.es/webbde/es/secciones/prensa/intervenpub/gobernador/mfo1105 10.pdf (consultado el 13/01/2013).

Fernández Rodríguez, C.J. (2007). El discurso del management: tiempo y narración. Madrid: CIS.

Fernández Rodríguez, C.J., Gantman, E.R. (2011). Spain and Argentina as importers of management knowledge (1955-2008): A comparative analysis. Canadian Journal of Administrative Sciences vol. 28, $n^{\circ} 2,160-173$.

Fishman, R.M. (1996). Organización obrera y retorno a la democracia en España. Madrid: CIS. 
FMI (2008). Spain: 2008 Article IV Consultation - Concluding Statement of the Mission. Disponible en: http://www.imf.org/external/np/ms/2008/120908.htm (consultado el 21/02/2013).

FMI (2010). Spain: 2010 Article IV Consultation - Concluding Statement of the Mission. Disponible en: http://www.imf.org/external/np/ms/2010/052410.htm (consultado el 16/02/2013).

Hall, S. (1988). The Hard Road to Renewal. Londres: Verso.

Hall, P. A., Soskice, D. (2001). Varieties of capitalism: the institutional foundations of comparative advantage. Nueva York: OUP.

Harvey, D. (2007). Breve historia del neoliberalismo. Madrid: Akal.

Ibáñez Rojo, R, López Calle, P (2012). La ficción del milagro económico español a la luz de la crisis financiera. Cuadernos de Relaciones Laborales. Vol. 30, $n^{\circ}$ 2, 379-407.

Koch, M. (2006). Roads to Post-Fordism: Labour Markets and Social Structures in Europe. Aldershot: Ashgate.

Laclau, E., Mouffe, C. (1984). Hegemony and Socialist Strategy: Towards a Radical Democratic Politics. Londres: Verso.

Lamo, A., Dolado, J. (1993). Un modelo de mercado de trabajo y la restricción de oferta en la economía española. Investigaciones Económicas. Vol. 17, $n^{\circ} 1,87-118$.

Lindbeck, A., Snower, D. (1988). The Insider-Outsider Theory of Employment and Unemployment. Cambridge, MA: MIT Press.

Locke. R.M., Thelen K. (1995). Apples and Oranges Revisited: Contextualised Comparisons and the Study of Labour Politics. Politics and Society. Vol. 23, $n^{\circ}$ 3, 337-367.

López, I., Rodríguez, E. (2010). Fin de ciclo: Financiarización, territorio y sociedad de propietarios en la onda larga del capitalismo hispano (1959-2010). Madrid: Traficantes de Sueños.

Malo, M.A. (2005). La evolución institucional del despido en España: Una interpretación en términos de un accidente histórico. Revista de Historia Económica, Vol. 23, $n^{o} 1,83-115$.

Malo, M.A., Toharia, L. (1999). Costes de despido y creación de empleo. Madrid: Ministerio de Trabajo y Asuntos Sociales. 
Manifiesto de los 100 (2009). Propuesta para la reactivación laboral en España. Available at: http://www.crisis09.es/PDF/restart-the-labor-market.pdf (consultado el 21/12/2012).

Manifiesto de los 700 (2009). El trabajo, fundamento de un crecimiento económico sostenible. Revista del Derecho de Extremadura. Vol. 5, 481-483.

Martínez Lucio, M. (1990). Trade unions and communism in Spain: The role of the CCOO in the political projects of the left. Journal of Communist Studies. Vol 6, $n^{\circ} 4,80-99$.

Martínez Lucio, M. (1991). Employer identity and the politics of the labour market in Spain, West European Politics. Vol. 14, $n^{\circ} 1,41-55$.

Martínez Lucio, M. (1998). Spain: Regulating employment and social fragmentation, en Ferner, A., Hyman, R. (eds.), Changing Industrial Relations in Europe (pp. 426-458). Oxford: Blackwell.

Martínez Lucio, M. (2002). Legitimar el mercado: el neoliberalismo y el 'juego' de la integración monetaria europea en España. Cuadernos de Relaciones Laborales. Vol. 20, $n^{\circ}$ 2, 385-409.

Martínez Lucio, M. (2008). ¿Todavía organizadores del descontento? Los retos de las estrategias de renovación sindical en España. Arxius de Ciencias Sociales. Vol. 18, 119-133.

Martínez Lucio M., Blyton, P. (1995). Constructing the post-Fordist state? The politics of labour market flexibility in Spain. West European Politics. Vol. 18, $n^{\circ} 2,344-366$.

Maurin, E. (2009). Le peur du dèclassement: Une sociologie des recessions. París: Éditions du Seuil / La République des Idées.

Miguélez, F., Prieto, C. (eds.) (1999). Las relaciones de empleo en España. Madrid: Siglo XXI.

Miguélez, F., Prieto, C. (2008). L'autre côté de la croissance de l'emploi en Espagne: une précarité qui se perpétue. Travail et Emploi. Vol. 115, 45-57.

Miguélez, F., Prieto, C. (2009). Transformaciones del empleo, flexibilidad y relaciones laborales en Europa. Política y Sociedad. Vol. 46, $n^{\circ}$ 1-2, 275-287.

Polavieja, J.G. (2003). Estables y precarios: desregulación laboral y estratificación social en España. Madrid: CIS.

Pries, L. (1988). Calificación, relaciones laborales y mercado de trabajo: el concepto de 'estrechez del ámbito empresarial' en España. Revista Española de Investigaciones Sociológicas. Vol. 41, 81-114. 
Prieto, C. (ed.) (2009). Calidad del empleo en España: una aproximación teórica y empírica. Madrid: Ministerio de Trabajo e Inmigración.

Rajoy, M. (2011). En confianza. Barcelona: Planeta.

Recio, A. (1994). Flexibilidad laboral y desempleo en España (reflexiones al filo de la reforma laboral). Cuadernos de relaciones laborales. Vol. 5, 57-74

Rodríguez Cabrero, G. (2009). La construcción sociohistórica de la reforma social en España. Ponencia invitada en el I Congreso REPS, Oviedo, noviembre 2009.

Rodríguez Ruiz, Ó., Martínez Lucio, M. (2010). The study of HRM in Spain: The Americanization of Spanish research and the politics of denial? The International Journal of Human Resource Management, vol. 21, $n^{\circ} 1,125-143$.

Rubery, J., Grimshaw, D. (2004). The Organisation of the Employment Relations. Londres: Palgrave.

Scullion, H., Collings, D.G., Gunnigle, P. (2007). International HRM in the $21^{\text {st }}$ Century: Emerging Themes and Contemporary Debates. Human Resource Management Journal. Vol. 17, $n^{\circ}$ 4, 309-319.

Smith, W.R. (1998). The Left's Dirty Job: The Politics of Industrial Restructuring in France and Spain. Pittsburgh, PA: University of Pittsburgh Press.

Toharia, L., Malo M.A. (2000). The Spanish experiment: Pros and cons of the flexibility at the margin, en Esping-Andersen, G., Regini, M. (eds.), Why Deregulate Labour Markets? (pp. 307-355). Oxford: OUP.

Toharia, L. (1986). Un fordismo inacabado entre la transición política y la crisis económica: España. En Boyer, R. (ed.), La flexibilidad del trabajo en Europa (pp. 161-184). Madrid: Ministerio de Trabajo y Seguridad Social.

Toharia, L. (2003). El mercado de trabajo en España, 1978-2003. Información Comercial Española, ICE: Revista de economía, Vol. 811, 203-220.

Valdés Dal-Ré, F., Ruesga Benito, S.Á., Zufiaur, J.L. (eds.) (2005). Transformaciones laborales en España: a XXV años de la promulgación del Estatuto de los Trabajadores. Madrid: Ministerio de Trabajo y Asuntos Sociales.

Valdés Dal-Ré, F., González-Posada Martínez, E., Valdés Alonso, A. (coords.) (2011). La reforma del mercado de trabajo de 2010. Madrid: Editorial Reus.

Zufiaur, J.L. (2009). La gota malaya de la reforma laboral. Relaciones laborales: Revista crítica de teoría y práctica, Vol. 2, 1193-1204. 